\title{
AS FUNDAÇÕES DE APOIO ÀS UNIVERSIDADES PÚBLICAS: EFEITOS DA REFORMA DO ESTADO NA EDUCAÇÃO SUPERIOR BRASILEIRA*
}

\author{
Fernando Henrique Protetti, \\ da Universidade Federal do $A B C$ \\ José VAIDERGORN, \\ da Universidade Estadual Paulista
}

\begin{abstract}
RESUMO: o artigo tem a finalidade de introduzir a discussão sobre as fundações de apoio às universidades públicas a partir dos efeitos produzidos pela reforma do Estado na Educação Superior brasileira na década 1990. Fundamentado na Sociologia Compreensiva de Max Weber e em pesquisa documental e bibliográfica, delimita sócio-historicamente o modelo gerencial de administração do Estado e o conceito de fundação. Ao identificar intersecções entre as orientações das fundações de apoio e os pressupostos da administração gerencial, apreende o significado dessas instituições na gestão universitária e a tendência à mercantilização da Educação Superior brasileira.
\end{abstract}

Palavras-chave: Fundações de apoio. Universidades públicas. Administração gerencial. Educação Superior-mercadoria.

\section{CONSIDERAÇÕES INICIAIS}

Ter como objeto de investigação as fundações de apoio às universidades públicas brasileiras não parece consistir em uma empresa simples, devido a sua inserção num universo controverso e ambíguo da Educação Superior brasileira. Primeiro, porque nos trabalhos disponíveis ${ }^{1}$ sobre o tema, observa-se a aproximação entre a análise propriamente científica e posições políticas e ideológicas dos atores inseridos nos debates desse setor (sindicatos de professores universitários, representantes e associações de entidades

* Artigo recebido em 15/08/2010 e aprovado em 10/09/2010. 
fundacionais, promotores e procuradores da administração pública etc.) $)^{2}$. Além disso, outro aspecto relevante é a própria dinâmica específica da esfera universitária, uma vez que boa parte das fundações de apoio é instituída pelos próprios docentes das mesmas universidades.

Apesar de ainda se apresentar insuficiente a produção sistemática do ponto de vista investigativo, nota-se que, recentemente, alguns trabalhos apresentam apreciações importantes sobre a realidade das fundações de apoio. Alves e Azevedo (2007), por exemplo, através da análise dos dados financeiros das fundações de apoio em duas universidades públicas, Universidade de São Paulo (USP) e Universidade Estadual de Maringá (UEM), e das relações estabelecidas entre fundação e universidade, indicam a necessidade da transparência financeira e da democratização da gestão das fundações de apoio, pois, estas "podem servir de alavanca para o avanço das atividades fins da IES (ensino, pesquisa e ensino) ou, ao contrário, podem estar servindo para satisfazer interesses de grupos, elites, oligarquias ou aristocracias internas." (p. 503)

Em trabalho apresentado na 32a Reunião Anual da Associação Nacional de Pós-Graduação e Pesquisa em Educação (ANPED), Ramos (2009) analisa as fundações de apoio pela identificação de elementos que sinalizam para a heteronomia universitária e o consequente desvirtuamento do ethos acadêmico. Considerando as fundações de apoio como "prescindíveis" às universidades, pois ferem os princípios constitucionais e ameaçam o acesso à Educação Superior e a autonomia universitária, Ramos $(2009$, p. 9) entende que as atuais "fundações são claramente incentivadas pelo Estado, que vem repassando recursos públicos obrigatoriamente por meio das mesmas", como no caso do Programa de Reestruturação das Universidades Federais (Reuni), sendo que é através dessas "que são firmados acordos de parceria público-privada que celebram contratos particularistas em detrimento da autonomia universitária."

Ainda no que tange à relação entre fundações de apoio e universidades públicas, Pereira (2009) analisa na sua dissertação o caso específico da Universidade Estadual Paulista Júlio de Mesquita Filho (UNESP), diagnosticando que o projeto de autonomia nas universidades públicas, especialmente nas estaduais paulistas, em consonância com a crescente redução no financiamento, tem apresentado como resultados a desvalorização do trabalho docente e a proliferação das fundações de apoio. Enquanto entidades dependentes da estrutura universitária que não atingem os fins proclamados, o apoio à pesquisa, ao ensino e à extensão, de acordo com Pereira (2009, p. 196), as 
fundações representam "a entrada direta dos interesses privados no seio da universidade, apoiando-se em regalias concedidas pelo poder público."

Frente às considerações acima e à publicação pelo Ministério da Educação (MEC) da Portaria n 920, de 20 de julho de 2010, que estabelece os procedimentos para o recadastramento de entiades sem fins lucrativos que atuam na área da educação, o presente artigo tem como finalidade introduzir a discussão sobre as fundações de apoio às universidades públicas a partir dos efeitos produzidos pela reforma do Estado na Educação Superior brasileira na década 1990, especialmente nos governos de Fernando Henrique Cardoso (FHC), de 1995 a 2002. A hipótese norteadora que se deseja verificar é se as atuais orientações às fundações de apoio às universidades públicas fundamentam-se nos pressupostos teórico-conceituais da administração gerencial.

Nesse sentido, o artigo se estrutura, primeiramente, pela delimitação sócio-histórica do modelo típico-ideal da administração gerencial do Estado, especialmente pelas referências ao pensamento de Bresser Pereira acerca das temáticas reforma do Estado e administração gerencial. No segundo momento, analisa-se o conceito de fundação a partir de pesquisa documental e bibliográfica, com o escopo de estabelecer uma tipologia das diferentes ações sociais da entidade fundacional. Posteriormente, com uma maior clareza sobre o conceito de fundação a partir desses pressupostos, procura-se compreender os pontos de interseção entre as fundações de apoio às universidades públicas e os fundamentos da administração gerencial. Ao final, realiza-se um balanço na procura de apreender o significado das fundações de apoio na gestão universitária e da tendência crescente ao processo de mercantilização da Educação Superior brasileira.

\section{A ADMINISTRAÇÃO GERENCIAL DO ESTADO}

Na literatura sobre reforma do Estado e administração gerencial, esta última também denominada nova administração pública ou administração pública gerencial, existe o aparente consenso de uma crise do Estado na contemporaneidade, principalmente no que tange à forma de sua administração, altamente burocratizada e de intervenção na sociedade civil e no mercado. Supõe-se que essa crise seria decorrente, primeiramente, de mudanças em escala mundial originadas na dimensão econômica e social, resultando em impactos significativos para a esfera estatal. Um segundo fator dessa crise proviria do novo papel do Estado frente às mudanças iniciadas na década de 1990, decorrentes do processo de mundialização e de suas consequências, transnacionalização do capital produtivo e financeiro, vertiginoso desenvol- 
vimento tecnológico e informacional, abertura dos mercados nacionais e reestruturação da produção e do trabalho.

Nessa mesma perspectiva da problemática, Pereira (1999a, p. 237) entende que a "crise do Estado implicou a necessidade de reformá-lo e reconstruí-lo; a globalização tornou imperativa a tarefa de redefinir suas funções. [...] Seu novo papel é o de facilitar que a economia nacional se torne internacionalmente competitiva." É desse modo, por uma "crise que se define como fiscal, como uma crise do modo de intervenção do Estado, como uma crise da forma burocrática pela qual o Estado é administrado, e, em um primeiro momento, também uma crise política" (PEREIRA, 1999a, p. 239), que no Brasil se cria, em 1995, o Ministério da Administração e Reforma do Estado (MARE). Através do seu Plano Diretor da Reforma do Aparelho do Estado, enquanto marco legal-normativo de definição diretiva das políticas públicas de reforma do Estado, esse Ministério objetivou efetivar a substituição do modelo de administração burocrático pela administração gerencial. No curto prazo da reforma, visava-se o ajuste fiscal das finanças estatais por meio da redução quantitativa de quadros administrativos, principalmente de estados e municípios, e de algumas ações estatais na dimensão do social. No médio prazo, almejava-se uma administração pública mais moderna e eficiente, ajustada às novas demandas sociais, econômicas e culturais, para inserir o país numa posição privilegiada no início do século XXI.

Com relação ao modelo da administração gerencial, Pereira (1999b, p. 28) define suas características básicas como uma forma de administração que é

orientada para o cidadão e para a obtenção de resultados; pressupõe que os políticos e os funcionários públicos são merecedores de grau limitado de confiança; como estratégia, serve-se da descentralização e do incentivo à criatividade e à inovação; e utiliza o contrato de gestão como instrumento de controle dos gestores públicos.

Nessa acepção, a administração burocrática, caracterizada por sua concentração no processo de modo lento, caro e ineficiente, deveria ceder lugar a um modelo de administração que delega no âmbito do Estado a sua autoridade pela descentralização política, dos recursos públicos e atribuições sociais, e pela descentralização administrativa. Igualmente, a administração gerencial representa uma forma de organização da esfera estatal com poucos níveis hierárquicos no quadro funcional, com disposição de um grau limitado de confiança em oposição à desconfiança total da administração burocrática. O controle dos resultados da ação estatal intermediada pelos contratos 
de gestão, instrumento de mediação das políticas públicas estatais, objetivavam, para o MARE, aumentar a qualidade do atendimento aos "serviços sociais" necessários à sociedade através do controle a posteriori dos processos administrativos. A modernização e eficiência da administração pública, no modelo gerencial, fortalecem nesse sentido a administração pública direta, denominada núcleo estratégico do Estado, e a descentralização de outras instâncias estatais. Ainda segundo Pereira (1999a, p. 258),

a proposta de reforma do aparelho estatal parte da existência de quatro setores dentro do Estado: a) o núcleo estratégico do Estado; b) as atividades exclusivas do Estado; c) os serviços não-exclusivos ou competitivos; e d) a produção de bens e serviços para o mercado.

As formas de propriedade e de administração para cada setor, bem como a alocação das distintas instituições estatais no âmbito desta divisão setorial, podem ser visualizadas a seguir:

Quadro 1 - Divisões de atividades do Estado moderno

\begin{tabular}{|l|l|l|l|l|l|}
\hline \multirow{2}{*}{ Setores do Estado } & \multicolumn{2}{|c|}{ Forma de propriedade } & \multicolumn{2}{c|}{ Forma de administração } \\
\cline { 2 - 5 } & Estatal & $\begin{array}{c}\text { Pública } \\
\text { não-estatal }\end{array}$ & Privada & Burocrática & Gerencial \\
\hline $\begin{array}{l}\text { Núcleo estratégico } \\
\text { Legislativo, Judiciário, } \\
\text { Presidência, Cúpula dos } \\
\text { Ministérios, Mistério Público }\end{array}$ & & & & \\
\hline $\begin{array}{l}\text { Atividades exclusivas } \\
\text { Regulamentação, Fiscalização, }\end{array}$ & & & & \\
$\begin{array}{l}\text { Fomento, Segurança Pública, } \\
\text { Seguridade Social Básica }\end{array}$ & & & & \\
\hline $\begin{array}{l}\text { Serviços não-exclusivos } \\
\text { Universidades, Hospitais, } \\
\text { Centros de Pesquisa, Museus }\end{array}$ & & & & \\
\hline $\begin{array}{l}\text { Produção para o mercado } \\
\text { Empresas estatais }\end{array}$ & & & & \\
\hline
\end{tabular}

Fonte: Autores, a partir de Brasil (1995).

Observa-se ser imprescindível que todos os setores do Estado tenham uma administração de característica gerencial, com exceção apenas do núcleo estratégico, caracterizado pela associação entre o modelo burocrático e gerencial. Essa ressalva se esclarece por ser esse setor o responsável pela definição de leis e políticas públicas no país. Com relação à forma de propriedade, nota-se a existência de um sentido peculiar atribuído pela administração gerencial à relação entre a clássica distinção das esferas 
pública e privada existente na administração burocrática. A esfera pública, para a administração gerencial, diferencia-se da esfera estatal devido à amplitude democrática e participativa atribuída ao espaço público, de modo a definir conceitualmente este último em duas outras novas esferas, estatal e não-estatal.

É pública a propriedade que é de todos e para todos. É estatal a instituição que detém o poder de legislar e tributar; é estatal a propriedade que integra o aparelho do Estado, sendo regida pelo direito administrativo. É privada a propriedade que se volta para o lucro ou para o consumo dos indivíduos ou dos grupos. De acordo com essa concepção, uma fundação "de direito privado", embora regida pelo direito civil, é uma instituição pública, na medida em que está voltada para o interesse geral. Em princípio, todas essas organizações sem fins lucrativos são ou devem ser organizações públicas não-estatais. Sem dúvida, poder-se-ia dizer que, afinal, continuamos apenas com as duas formas clássicas de propriedade: a pública e a privada, mas com duas importantes ressalvas: primeiro, a propriedade pública se subdivide em estatal e nãoestatal, ao invés de se confundir com a estatal; e segundo, as instituições de direito privado voltadas para o interesse público e não para o consumo privado não são privadas, e sim públicas não-estatais. (PEREIRA, 1999a, p. 262, grifos nossos)

Ainda de acordo com o Quadro 1, a propriedade estatal inclui os setores do núcleo estratégico e as atividades exclusivas do Estado; pela privatização das empresas estatais, o setor estatal da produção para o mercado localiza-se no âmbito da propriedade privada. Finalmente, para o setor de serviços não-exclusivos, no qual são incluídas as universidades públicas, a forma de propriedade mais apropriada corresponde à pública não-estatal, ou seja, a uma esfera pública de direito privado, não estatal. Esse processo da transformação dos serviços não-exclusivos do Estado em público não-estatal, segundo as propostas do MARE, seria efetivado pelo programa de publicização, com o objetivo da dotação e geração de autonomia financeira e administrativa das instituições envolvidas sob a forma jurídica das Organizações Sociais (BRASIL, 1995).

Nesse sentido, evidencia-se na proposta da administração gerencial a existência de um movimento pragmático de ressignificação conceitual com relação às esferas pública e privada. Esse fenômeno não é atípico, mas tem-se tornado, cada vez mais, lugar comum. Com relação ao campo da Educação, por exemplo, Moraes (2003) denomina esse movimento recuo da teoria, o que significa a existência de um ceticismo que não é apenas epistemológico mas também ético e político nas formulações teóricas. No caso específico das categorias Estado e político, a ressignificação apresenta-se pelas ideias alternativas 
existentes sobre a sociedade civil. Na concepção de sociedade civil liberalista, da administração gerencial, o mercado ocupa o eixo predominante e"o Estado mostra-se como o outro lado tanto do mercado e da sociedade civil, como de eventuais alianças ou combinações entre eles." (NogueirA, 2003, p. 192) O que Bresser Pereira denomina público não-estatal, portanto, corresponde a uma sociedade civil em que a questão da hegemonia não teria espaço.

Em decorrência, o Estado que corresponde a essa sociedade civil é um Estado mínimo, reduzido às funções de guarda da lei e da segurança, mais liberal e representativo do que democrático e participativo.

Nessa concepção, a sociedade civil é externa ao Estado - uma instância pré-estatal ou infra-estatal -, e nela se busca compensar a lógica das burocracias públicas e do mercado com a lógica do associativismo sociocultural. (NoguelRA, 2003, p. 192, itálico do autor)

Esse espectro do associativismo sociocultural tem, para a concepção gerencial, significado na ideia de que a sociedade civil é passível de organização pela sua própria lógica, representada pelas diferentes configurações jurídicas do Terceiro Setor, como as Organizações Sociais (OS), Organizações da Sociedade Civil de Interesse Público (OSCIP), Organizações não-governamentais (ONG), Fundações de Interesse Público, dentre outras, detentoras de administração própria e de autonomia política e financeira. O emergente Terceiro Setor, compreendido como a sociedade civil organizada e localizada entre os setores do Estado (Primeiro Setor) e do mercado (Segundo Setor), é visto pela administração gerencial como parceiro importante das distintas políticas governamentais, uma vez que tais instituições sempre objetivam a busca de interesses comuns e demandam recursos públicos para iniciativas do interesse público. Portanto, uma sociedade civil concebida desse modo, como esfera própria e vazia de tensões, disputas e contradições sociais, na

sua configuração típico-ideal, [...] produz incentivos basicamente competitivos; re-fragmentação, fechamento corporativo dos interesses, despolitização. Nela tendem a se articular movimentos direcionados para valorizar interesses particulares, atender demandas, fiscalizar governos, desconstruir e desreponsabilizar o Estado, enfraquecer ou desativar dispositivos de regulação. (NogueiRA, 2003, p. 193)

\section{AS FUNDAÇÕES DE APOIO ÀS UNIVERSIDADES PÚBLICAS}

O modelo gerencial de administração do Estado, acima esboçado, parece indicar alguns subsídios preliminares possíveis para se verificar em que medida existem (ou não) relações dos seus pressupostos teórico-conceituais 
com o papel das fundações de apoio às universidades públicas. Assim, neste momento, empreende-se uma delimitação do conceito sócio-histórico de fundação, considerando a literatura bibliográfica e documental sobre o tema, com o intuito de estabelecer relações entre esse conceito e os distintos momentos histórico-sociais da Educação Superior brasileira. Em seguida, a preocupação centra-se na compreensão das possíveis aproximações entre administração gerencial e as fundações de apoio, através da identificação dos seus elementos comuns.

\section{NOTAS SOBRE O CONCEITO SÓCIO-HISTÓRICO DE FUNDAÇÃO}

O direito, como instrumento estatal legitimado de dominação social, pode assumir duas formas de emprego: primeiro, como direito objetivo (norma agendi), que possibilita uma visão macro das normas legais de modo positivo e racional das relações dos homens entre si e seu convívio em sociedade, e, segundo, como direito subjetivo (facultas agendi) que proporciona aos sujeitos diferentes ações sociais.

Para o sociólogo alemão Max Weber (1999, p. 3), toda e qualquer ação representa um comportamento humano relacionado com o seu sentido subjetivo, porém, o aspecto essencial da investigação sociológica é a análise da ação social, "uma ação que, quanto ao seu sentido visado pelo agente ou os agentes, se refere ao comportamento de outros, orientando-se por este em seu curso". Através do que denomina Sociologia Compreensiva, "ciência que pretende compreender interpretativamente a ação social e assim explicá-la causalmente em seu curso e em seus efeitos", Weber observa que as ações sociais podem ser ocasionadas por quatro diferentes possibilidades: de modo (1) racional referente $a$ fins, ação social em que seu sentido com relação a objetos e pessoas do mundo externo para o indivíduo utiliza enquanto orientação as avaliações das condições ou meios para se atingir determinados fins de forma racional; (2) racional referente a valores, uma ação social que considera para sua efetivação um determinado valor absoluto (ético, estético, religioso etc.) que se constitui como inerente à ação, independentemente do resultado desta, muitas vezes se aproximando da ação irracional; (3) afetiva, uma ação orientada por afetos ou estados emocionais do indivíduo; e, finalmente, (4) tradicional, ação social exercida pela orientação de um "costume arraigado" (idem, itálicos do autor). Destarte, destacam-se para a identificação das principais formas histórico-sociais do conceito de fundação no Brasil o referencial das duas primeiras formas de ação social: racional referente a fins e racional referente a valores, conjugadas segundo diferentes possibilidades. 
a) Fundação e a ação social racional referente a valores: a primeira vez que o conceito de fundação foi usado como pessoa jurídica na legislação brasileira data do ano de 1903, com a Lei Ordinária $n^{\circ} 173$, que conferia personalidade jurídica a entidades com fins literários, científicos e religiosos (Grazziolı, Rafael, 2009). Com a aprovação do Código Civil de 1916, observam-se as primeiras delineações legais para as pessoas jurídicas no direito público e no direito privado, bem como as normas e regras internas e externas ${ }^{3}$.

Entretanto, para o delineamento sócio-histórico do conceito de fundação no Brasil, encontra-se seu marco em 1783, a partir da criação da instituição conhecida como Casa da Roda. Enquanto um fundo patrimonial de amparo às crianças órfãs da cidade do Rio de Janeiro que funcionava paralelamente à Santa Casa de Misericórdia da cidade, essa fundação foi criada com a doação de parte da riqueza de um solteiro milionário chamado Romão de Matos Duarte. Nota-se que a criação dessa primeira fundação brasileira está em consonância com uma ação racional referente a valores, no caso, uma ação de benevolência, de caridade, com características religiosas, aliás, um tipo-ideal de ação social muito próximo da origem das primeiras fundações na Idade Média, entidades que tinham como objetivo uma ação filantrópica (piae causae) no âmbito do regime jurídico vigente.

Esse modelo fundacional aos poucos perde espaço, em decorrência da decadência da hegemonia da Igreja Católica, para uma nova configuração de fundação sob a figura do mecenas, que destinava parte de suas riquezas para uma finalidade específica, principalmente atividades culturais, científicas e artísticas. O conceito de fundação, desse modo, relaciona-se enfim com a emergência de um espírito laico de características autônomas e de orientação privada (Grazziolı, Rafael, 2009).

b) Fundação e as ações sociais racionais referentes a valores e a fins: outra possibilidade da compreensão sócio-histórica do conceito de fundação, agora sob a realidade da Educação Superior brasileira, pode ser demarcada pela criação das universidades federais durante a década de 1960. Um primeiro momento desse período caracteriza-se pela criação das universidades fundacionais em detrimento das universidades autárquicas. Intelectuais como Anísio Teixeira e Darcy Ribeiro, ainda no início de 1960, defendiam a adoção do modelo fundacional com a justificativa de que sua estrutura jurídica possibilitava maior autonomia didática, técnica, científica e administrativa às universidades federais, liberando-as, portanto, dos entraves burocráticos dos órgãos da administração federal. A criação da Fundação Universidade de Brasília (FUB), pela aprovação da Lei 3.998 de 15 de dezembro de 1961, 
fornece significativo exemplo desse processo, como bem o salienta Morhy (2005, p. 2-3), ex-reitor da universidade entre 1997 e 2005.

Para viabilizar a UnB como experiência inovadora e livrá-la das amarras da burocracia oficial e suas consequências destruidoras de qualquer projeto de universidade que realmente mereça essa designação, seus idealizadores criaram a FUB. [...] Figura nova no poder público brasileiro, esperava-se que uma fundação pudesse contornar os obstáculos e lubrificar o ranço da administração pública e seus rigores legalistas e jurisdicistas. Esperava-se introduzir, no serviço público universitário, as ideias e as técnicas mais ágeis e eficientes da iniciativa privada; a busca de modos mais razoáveis de tratar e remunerar o pessoal e, enfim, toda uma cultura de gestão mais aberta e compatível com a autonomia universitária.

Entretanto, com o golpe militar de 1964, a original flexibilidade administrativa propiciada pelo regime fundacional altera-se para uma nova função, determinando um segundo momento. Inicialmente, os DecretosLei $n^{\circ} 200$, de 25 de fevereiro de 1967, e n 900, de 29 de setembro de 1969, limitam o regime jurídico fundacional ao tornar as universidades federais menos autônomas e flexíveis (SGUISSARDI, 1993). Com a implementação da Reforma Universitária, aprovada pela Lei no 5.540, de 28 de novembro de 1968, verifica-se o controle político-ideológico exercido pelo Conselho de Curadores das fundações através da redação do artigo 15 dessa lei .

Constatando a existência destes componentes, Sguissardi (1993) denomina esse momento histórico da Educação Superior brasileira como o "tempo das fundações", isto é, período marcado pela adoção sistemática do modelo fundacional para as novas universidades em contraposição ao modelo autárquico, a primeira com forte tendência descentralizadora, já a segunda com característica mais centralizada. Nesse binômio centralização versus descentralização, o autor observa que

entretanto, essa expansão das organizações de uma administração pública descentralizada não trouxe somente vantagens, do ponto de vista do poder central. Este teve e tem que lutar para retomar o controle e coordenação deste segmento da administração pública.

Esta tendência, que se verifica na administração pública em geral, durante os últimos 30 anos, se manifesta especialmente junto às Universidades Federais Fundações. Por um lado, pretendeu-se dotar as universidades de mecanismos mais ágeis, de maior plasticidade, de menor burocracia, para seu funcionamento; por outro, buscaram-se formas de mantê-las sob controle político administrativo. E o mecanismo primeiro e mais utilizado tem sido, como se verá, mais adiante, o do controle orçamentário, o do controle da expansão de cursos e custos, via proibição sistemática de novas contra- 
tações ou de expansão do quadro de servidores, via rebaixamento real de salários, via nomeação unilateral de seus dirigentes, tanto conselheiros do Conselho Diretor ou de Curadores quanto reitores e diretores de unidades etc. (SGUISSARDI, 1993, p. 48)

Observa-se que a adoção do modelo fundacional para a criação das universidades indica a existência de duas orientações que permeariam a ação social do Estado brasileiro no período. Primeiramente, o modelo fundacional possuía a finalidade de dotar as instituições universitárias recém-criadas de maior autonomia organizacional, financeira e administrativa; portanto, uma ação social caracteristicamente racional referente a fins. Contudo, com o golpe militar de 1964, marcado pelo autoritarismo político, a adoção do modelo fundacional nas universidades permitirá o controle político-administrativo estatal na direção de uma ação social referente a valores, ou seja, uma ação de valor absoluto, no caso particular analisado, o da dominação política da realidade social universitária através da esfera estatal.

c) Fundação e ação social racional referente a fins: atualmente, a definição do conceito de fundação como ente institucional concebido segundo uma pessoa jurídica é regulado pela Lei $n^{\circ}$ 10.406, de 10 de janeiro de 2002, que institui o Código Civil. Segundo essa lei, as pessoas jurídicas podem assumir a feição de direito público e privado; as primeiras, pela figura da União, estados, municípios, autarquias e entidades de caráter público criadas mediante lei (artigo 41); e as segundas, como associações, sociedades, organizações religiosas, partidos políticos e fundações (artigo 44) (BRASIL, 2002). De acordo com o jurista Dallari (1995, p. 17),

fundação é a vinculação de um patrimônio a determinado fim, dando-lhe personalidade jurídica. Numa fórmula sintética, pode-se dizer que fundação é um patrimônio personalizado, o que significa que o patrimônio adquire a condição de pessoa, passando a ser sujeito de direitos, ao mesmo tempo em que pode assumir obrigações jurídicas. Em termos mais concretos, pode ser proprietária e receber doações, pode mover ações judiciais, podendo, em síntese, agir como se fosse uma empresa legalmente constituída. Além disso, fica sujeita ao cumprimento de obrigações, como o pagamento de impostos e o respeito aos compromissos que tiver assumido com terceiros; ficando, ainda, sujeita a algumas regras legais que só se aplicam às fundações, como o controle permanente pelo Ministério Público.

Considerando esses pressupostos, as fundações de apoio às universidades são compreendidas como um patrimônio personalizado por pessoas naturais ou jurídicas de direito privado e têm como finalidade principal o apoio às instituições públicas de ensino superior, de extensão, de pesquisa e de de- 
senvolvimento tecnológico. A Lei n 8.958, de 20 de dezembro de 1994, que versa sobre as relações entre instituições federais de Educação Superior (IFES) e de pesquisa científica e tecnológica e as fundações de apoio, possibilitou que estas últimas fossem credenciadas pelo MEC e MCT (Ministério de Ciência e Tecnologia), enquanto "um tipo especial de fundação de direito privado, o que lhe assegura algumas vantagens e regalias; dentre elas, destaca-se a dispensa de licitação para contratar com entidades públicas." (TRISTÃO, 2000, p. 6). A principal característica das fundações de apoio é representada pela captação de recursos para apoiar ações de pesquisa, ensino e extensão, teoricamente no âmbito da universidade que apoiam. No entanto,

todas as fundações de apoio às instituições de ensino superior desenvolveram portfólio de serviços e produtos para a captação de recursos. E, por sua vez, apoiam supletivamente as suas instituições. Sem elas, as Universidades Federais não conseguiriam manter seus atuais padrões de qualidade. (TRISTÃo, 2000, p.5)

Nesse sentido, as universidades federais, bem como as estaduais, têm cada vez mais adotado opções variadas de captação de recursos próprios como mecanismo de complementação das receitas auferidas pela administração central, provindas, nesse caso, do MEC, destacando-se as atividades de prestação de serviços diversos, como assessorias técnicas e científicas, realização de concursos públicos, com destaque especial para a oferta de cursos de especialização (pós-graduação lato sensu). Para Schwartzman (2006, p. 9), as fundações de apoio,

em anos mais recentes, especialmente na década de 90 , passaram, também, a ser importantes veículos de captação de recursos, que tinham como principal objetivo a complementação de salários de servidores e de recursos extras para unidades e departamentos. Esta foi a resposta encontrada para a crescente dificuldade de recursos de OCC [Outros Custeios e Capital] e para a contenção salarial. De fato, hoje existem mais de 100 fundações ligadas às IFES, que se tornaram um essencial suporte na captação de recursos extras, principalmente aqueles oriundos da prestação de serviços e do oferecimento de cursos de extensão.

Nas observações realizadas acima sobre o conceito de fundação pela materialização das funções e atividades das fundações de apoio às universidades, com destaque para as universidades públicas no decorrer da década de 1990, é possível inferir analiticamente que a ação social empregada por essas formações sociais aproxima-se singularmente de uma ação social racional referente a fins. Isso significa apreender que, pela avaliação 
dos meios existentes na Educação Superior brasileira, tais como a diminuição de recursos e financiamento da esfera estatal e a probabilidade efetiva de angariar recursos através de atividades de ensino, pesquisa e extensão no mercado, o sentido atribuído às fundações de apoio a suas próprias ações visa uma orientação para determinados fins de modo racional, ou seja, ações com objetivos racionais privados de apoio às universidades.

\section{APROXIMAÇÕES ENTRE AS FUNDAÇÕES DE APOIO E A ADMINISTRAÇÃO GERENCIAL}

Ao analisar o conceito de fundação e sua relação com diferentes tipos de ações sociais no contexto sócio-histórico brasileiro, de modo a fornecer subsídios compreensivos, a preocupação neste momento centra-se nas aproximações possíveis entre os fundamentos da administração gerencial e as fundações de apoio às universidades. Para isso, deter-nos-emos especificamente no período dos dois governos de FHC (1995-1998 e 1999-2002), ocasião do processo de reforma do Estado influenciado pelas concepções gerenciais de administração, como já salientado anteriormente na análise da administração gerencial do Estado, e, ainda, por existir nesse período certa homogeneidade nas políticas educacionais para a Educação Superior. $\mathrm{Na}$ tabela 1, verifica-se a quantidade de fundações de apoio às universidades federais credenciadas junto ao MEC e MCT entre o período de 1995 a 2002:

TABELA 1 - Evolução do número de fundação de apoio às IFES credenciadas pelo MEC e MCT entre 1995-2001

\begin{tabular}{|c|c|}
\hline Ano & Número de fundações credenciadas \\
\hline 1995 & 42 \\
\hline 1996 & 52 \\
\hline 1997 & 61 \\
\hline 1998 & 68 \\
\hline 1999 & 79 \\
\hline 2000 & 88 \\
\hline 2001 & 96 \\
\hline
\end{tabular}

Fonte: Amaral (2003).

Nesses dados, é possível reconhecer que houve no período um crescimento expressivo do número de fundações de apoio credenciadas: de 42 existentes em 1995, esse número passa para 96 instituições em 2001, aumento correspondente a 129\%. A partir dessa constatação, quais seriam, então, as influências principais da administração gerencial do Estado na orientação da expansão significativa dessas instituições no âmbito das universidades 
públicas? Para a resposta a essa questão, apresentam-se, a seguir, três aproximações entre as ideias desenvolvidas até este momento.

I-O processo de ressignificação conceitual efetivado pela concepção gerencial dos conceitos de propriedade pública e privada para os de propriedade estatal, privada e pública não-estatal, proporcionou às fundações de apoio uma legitimidade de conhecimento científico e uma relevância social, devidos a seu enquadramento na esfera da propriedade pública não-estatal. Pela sua inserção, enquanto instituição social que compõe o Terceiro Setor, na ótica gerencial de uma sociedade civil organizada, sem conflitos, e com clareza dos interesses públicos, as fundações de apoio gozaram de terreno favorável para sua difusão no domínio da Educação Superior brasileira.

II - A divisão e definição dos setores da esfera estatal empreendida pela administração gerencial, por sua vez materializada em ação política pelo Plano Diretor da Reforma do Aparelho do Estado do MARE, apresentavam as universidades federais como instituições públicas inseridas no setor de serviços não-exclusivos do Estado, as quais deveriam transformar-se em organizações sociais através do programa de publicização, quando então seriam dotadas de autonomia administrativa e financeira para a captação de recursos próprios. Com a forte oposição da comunidade acadêmica, principalmente das associações de docentes e de pesquisadores, a esse ideal gerencial, o que, de fato, produziu resultados concretos, as fundações de apoio enquanto instituições alocadas entre o Estado e as universidades, amparadas em normatizações legais, aos poucos tomaram para si essa função de angariar recursos, sobretudo no contexto de restrição salarial dos servidores e congelamento de investimentos no setor.

III - Mesmo não se tendo efetivado plenamente segundo os pressupostos ambicionados, em associação à criação de uma constelação de normatizações legais e jurídicas de regulação dos setores da Educação Superior e das organizações sociais emergentes da sociedade civil no período dos governos de $\mathrm{FHC}$, o conjunto teórico-conceitual da administração gerencial a respeito da existência de uma efetiva crise do Estado e da necessidade da sua reforma para adequação a uma nova realidade sócio-econômica contemporânea possibilitou a emergência e difusão de um novo paradigma no campo científico da Educação Superior, combinado em dois elementos inter-relacionados: (1) as restrições e limitações financeiras e orçamentárias da esfera estatal para o financiamento das IES públicas, e, (2) a legalidade e legitimidade jurídica das ações realizadas pelas fundações de apoio, ainda que para alguns pesquisadores essas ações estejam muitas vezes próximas de um quase mercado educacional. 


\section{CONSIDERAÇÕES FINAIS}

O percurso realizado neste artigo procurou introduzir o leitor na problemática das fundações de apoio às universidades públicas na perspectiva da relação sócio-histórica existente entre o modelo típico ideal da administração gerencial do Estado e o conceito de fundação. Os pontos de intersecção observáveis entre a concepção gerencial da esfera estatal e as principais características das fundações de apoio às universidades públicas possibilitaram compreender casualmente como o processo de reforma do Estado nos governos de FHC (1995-2002) refletiu acentuadamente na Educação Superior brasileira, o que foi identificado neste artigo pelo crescente papel que as fundações de apoio têm ganhado no processo de gestão das universidades públicas.

Talvez, uma das questões mais fundamentais elaboradas sobre a compreensão das fundações de apoio tenha sido formulada por Sguissardi (2002), através da pergunta que representa o próprio título do seu trabalho, Fundações Privadas na Universidade Pública: a quem interessam? A reposta para essa dúvida, devido à contradição do real e da situação paradoxal dessas entidades na Educação Superior, contém, segundo o autor, distintas repostas, cujo destaque integral, apesar da extensão, considera-se fundamental:

1) a todos os que, na ausência de efetiva autonomia administrativa e de gestão financeira das IES, buscaram meios de garantir maior flexibilidade, agilidade administrativa na gerência de projetos e de recursos, para que as atividades-fim (ensino, pesquisa e extensão) da universidade fossem atingidas, evitando, na medida das possibilidades legais, os riscos inerentes à natureza dessas entidades (privadas, formalmente sem fins lucrativos) de fugirem de sua destinação original - apoio institucional - e se constituírem em efetivos enclaves privados no interior de instituições públicas; 2 ) aos que, não acreditando ou não levando a sério a legitimidade e especificidade da missão pública da universidade, quando, no dizer de [Boaventura de] Souza Santos, "a mercantilização do modo de estar no mundo está a converter-se no único modo racional de estar no mundo mercantil", optaram por se utilizar desta possibilidade legal para, a pretexto de prover recursos para as IES cada vez mais deles desprovidas, agirem livremente no mercado ou no quasemercado, como se tudo na universidade - ensino, pesquisa, extensão - fosse mercadoria ou quase-mercadoria regulável pelas leis do mercado; 3) aos que, acreditando em teses como as de um menor retorno social dos investimentos no ensino superior do que o dos investimentos na Educação Básica, de que a Educação Superior é atividade competitiva e de que o Estado deve ter um papel subsidiário neste nível de educação, defendem a transformação das IES públicas em organizações sociais, entidades ditas públicas não estatais, 
conforme proposta inclusa no Plano Diretor da Reforma do Estado, do MARE. (SGUISSARDI, 2002, p. 90-1, itálico do autor)

Ainda que essas respostas contenham uma nitidez ímpar, elas parecem não contemplar em parte a finalidade almejada neste trabalho. Nesse sentido, foi possível verificar como as fundações de apoio às universidades públicas passaram a figurar no transcorrer da década de 1990 como instituições sociais privadas originadas pela reforma do Estado na Educação Superior brasileira, assumindo cada vez mais a função de subsidiar e auxiliar o financiamento estatal para o desenvolvimento e a manutenção das atividades-fim das universidades públicas (pesquisa, ensino e extensão), contudo, protegidas por dispositivos legais e normativos e legitimadas pela concepção da administração gerencial. No entanto, o maior dos problemas a respeito das fundações de apoio parece incidir na tensão existente na Educação Superior brasileira entre a ameaça e o enfraquecimento do espaço público frente ao espaço privado, dado pelo processo de mercantilização dessa educação. As atividades desempenhadas pelas fundações de apoio às universidades públicas figuram a partir de uma lógica de regulação de mercado, segundo critérios como a competição, a livre escolha, a ação empreendedora individual ou associada dos atores inseridos nessas instituições.

Tal como o narrador de Poe (1993), no conto O Homem da multidão, observava e categorizava os transeuntes londrinos até o momento em que a estranha figura de um velho lhe chamou a atenção, e então, seguindo seu trajeto durante dia e noite, chega à conclusão de que se tratava de um "tipo e o gênio do crime profundo" (p. 51), acredita-se que seja imprescindível a continuidade das investigações sobre a realidade teórica e prática das fundações de apoio, para que estas não se tornem para as universidades públicas o seu "Homem da multidão".

SUPPORT FOUNDATIONS FOR PUBLIC UNIVERSITIES: EFFECTS OF STATE REFORM ON BRAZILIAN HIGHER EDUCATION

ABSTRACT: The article discusses support foundations for public universities starting from the effects of State reform on Brazilian higher education in the 1990s. Based on Max Weber's Comprehensive Sociology and on bibliographical and documentary research, it socio-historically circumscribes the management model of State administration and the concept of foundation. As one identifies the intersections between the guidelines of support foundations and the purposes of managerial administration, one understands the significance of such institutions for university management and the tendency towards commodification of Brazilian higher education. 
KEYWORDS: Support Foundations. Public Universities. Managerial Administration. Higher Education as a commodity.

\section{NOTAS}

1. Uma primeira versão deste trabalho foi apresentada na forma de comunicação no Il Seminário de Educação Brasileira: os Desafios Contemporâneos para a Educação Brasileira e os Processos de Regulação, promovido pelo Centro de Estudos Educação e Sociedade (CEDES), da Universidade Estadual de Campinas (UNICAMP), em dezembro de 2009. Neste texto, realizou-se um refinamento analítico com relação ao anterior. Agradecemos ao Professor Valdemar Sguissardi pelas críticas e sugestões ao trabalho.

2. Sobre esse aspecto destacam-se, como exemplo, o conjunto de documentos produzidos e disponibilizados pela Associação dos Docentes da Universidade de São Paulo (ADUSP), intitulado Dossiê Fundações (Disponível em: http://www.adusp. org.br/dossies/fundacoes/default.htm. Acesso em: 15 de out. 2010), e os artigos, as publicações, os vídeos etc. produzidos pela Associação Paulista de Fundações (APF) (Disponível em: http://www.apf.org.br/portal. Acesso em: 15 de out. 2010).

3. No Código Civil de 1916, lê-se que "as pessoas jurídicas são de direito público, interno, ou externo, e de direito privado." A União, os estados, o Distrito Federal e os municípios são pessoas jurídicas de direito público (artigo 14), enquanto as sociedades civis, religiosas, pias, morais, científicas ou literárias, as associações de utilidade pública, as fundações e as sociedades mercantis, pessoas jurídicas de direito privado (artigo 16).Com exceção das sociedades mercantis, todas as demais pessoas jurídicas de direito privado deveriam destinar o seu patrimônio a um determinado fim social (BRASIL, 1916).

4. "Em cada universidade sob forma de autarquia especial ou estabelecimento isolado, mantido pela União, haverá um Conselho de Curadores, ao qual caberá a fiscalização econômico-financeira" (artigo 15), fazendo parte desse Conselho "na proporção de um terço deste, elementos estranhos ao corpo docente e ao discente da universidade ou estabelecimento isolado, entre os quais representantes da indústria" (parágrafo único), incluindo ainda, "além dos membros pertencentes à própria instituição, representantes da comunidade e do Ministério da Educação e Cultura, em número correspondente a um terço do total" (parágrafo único) (BRASIL, 1968).

\section{REFERÊNCIAS}

ALVES, A. M. S.; AZEVEDO, M. L. N. Fundação de apoio à universidade: uma discussão sobre o conflito entre o público e o terceiro setor. Atos de Pesquisa em Educação, Blumenau, v. 2, n. 3, p. 486-507, set./dez. 2007.

AMARAL, N. C. Financiamento da Educação Superior: Estado x mercado. São Paulo: Cortez Editora; Piracicaba: Editora UNIMEP, 2003. 
BRASIL. Lei no 10.406, de 10 de janeiro de 2002. Institui o Código Civil. Diário Oficial [da] República Federativa do Brasil, Brasília, 11 jan. 2002. Disponível em: <http://www. planalto.gov.br/ccivil_03/Leis/2002/L10406.htm>. Acesso em: 30 ago. 2010.

- Ministério da Administração Federal e Reforma do Estado. Plano Diretor da Reforma do Aparelho do Estado. Brasília, 1995.

. Lei $n^{\circ} 5.540$, de 28 de novembro de 1968. Fixa normas de organização e funcionamento do ensino superior e sua articulação com a escola média, e dá outras providências. Diário Oficia da União, Brasília, 23 nov. 1968. Disponível em: <http:// www.planalto.gov.br/ccivil_03/Leis/L5540.htm>. Acesso em: 3 abr. 2010.

. Lei n 3.071, de 1º de janeiro de 1916. Código Civil dos Estados Unidos do Brasil (revogado pela Lei no 10.406, de 10 de janeiro de 2002). Disponível em: <http:// www6.senado.gov.br/legislacao/ListaPublicacoes.action?id=102644>. Acesso em: 30 ago. 2010.

DALLARI, D. A. Fundações Públicas e suas limitações. Revista ADUSP, São Paulo, p. 16-19, jul. 1995.

GRAZIOLI, A.; RAFAEL, E. J. Fundações privadas: doutrina e prática. São Paulo: Atlas, 2009.

MORAES, M.C. M. de. Recuo da teoria. In:

(Org.). Iluminismo às avessas: produção de conhecimento e políticas de formação docente. Rio de Janeiro: DP\&A, 2003, p. 151-168.

MORHY, L. FUB-UnB: 40 anos! UnB revista, Brasília, Ano II, n. 5, jan./fev./mar. 2002. Disponível em:<http://www.lauromorhy.com.br/artigos/FUB-UnB_40_anos_jan2002. pdf> Acesso em: 4 jun. 2010.

NOGUEIRA, M. A. Sociedade civil, entre o político-estatal e o universo gerencial. Revista Brasileira de Ciências Sociais, São Paulo, v. 18, n. 5, p.185-202, jun. 2003.

PEREIRA, L. C. B. Da administração pública burocrática à gerencial. In: ;SPINK, P. K. (orgs.). Reforma do Estado e administração pública gerencial. 3. ed. Rio de Janeiro: Editora FGV, 1999a, p. 237-270.

.Gestão do setor público: estratégia e estrutura para um novo Estado. In:

SPINK, P. K. (orgs.). Reforma do Estado e administração pública gerencial. 3. ed. Rio de Janeiro: Editora FGV, 1999b, p. 21-38.

PEREIRA, C. M. C. Fundações privadas e precarização do trabalho docente na UNESP: 1995-2008. 2009. 206 f. Dissertação (Mestrado em Educação Escolar) - Universidade Estadual Paulista Júlio de Mesquita Filho, Araraquara-SP, 2009.

POE, E. A. O Homem da multidão. Porto Alegre: Paraula, 1993.

RAMOS, G. S. As fundações de apoio privadas: notas para a análise de uma realidade heteronômica. In: 32a Reunião Anual da ANPED, 2009, Caxambu. Anais eletrônicos... Disponível em: <http://www.anped.org.br/reunioes/32ra/arquivos/trabalhos/GT115920--Int.pdf>. Acesso em: 10 nov. 2009. 
SCHWARTZMAN, J. O financiamento das instituições de ensino superior no Brasil. In: STEINER, J. E.; MALNIC, G. (orgs.). Ensino superior: conceito \& dinâmica. São Paulo: Instituto de Estudos Avançados da USP, Co-edição IEA e Edusp, 2006. Disponível em: <http://www.iea.usp.br/iea/tematicas/educacao/superior/autonomiafinanciamento/ schwartzmanfinanciamento.pdf $>$. Acesso em: 20 jul. 2009.

SGUISSARDI, V. Fundações Privadas na Universidade Pública. A quem interessam? Avaliação, Sorocaba, v. 7, n. 4, p. 74-97, dez. 2002.

. Universidade, fundação e autoritarismo: o caso da UFSCar. São Paulo: Estação Liberdade; São Carlos: Editora da UFSCar, 1993.

TRISTÃO, G. O papel das fundações na modernização das universidades federais. In:V Congreso Interenacional del CLAD sobre la Reforma del Estado y da la Administración, 2000, Republica Dominicana. Anais eletrônicos... Disponível em: <http://unpan1.un.org/ intradoc/groups/public/documents/CLAD/clad0038519.pdf.>. Acesso em: 17 jul. 2009.

WEBER, M. Economia e Sociedade: fundamentos da sociologia compreensiva. Brasília: Editora UnB; São Paulo: Imprensa Oficial do Estado de São Paulo, 1999, Vol. I.

JOSÉ VAIDERGORN, sociólogo, mestre e doutor em Educação pela FEUnicamp, é professor do Departamento de Ciências da Educação da FCL/UNESP, Campus de Araraquara, coordenador do Programa de Pós-Graduação em Educação Escolar (2003-2006 e 2010-2013). Curriculum Lattes: http://lattes.cnpq.br/9258095769277556

E-mail: jose_v@fclar.unesp.br

Fernando Henrique Protettl, sociólogo, é mestre, com bolsa da CAPES, em Educação Escolar pela Faculdade de Ciências e Letras da Universidade Estadual Paulista (UNESP), de Araraquara, linha de pesquisa Política e Gestão Educacional, técnico em Assuntos Educacionais na Universidade Federal do $A B C$ (UFABC) e Tutor à distância do Bacharelado em Administração Pública na Universidade Federal de Lavras (UFLA).

Curriculum Lattes: http://lattes.cnpq.br/3049488929722720

E-mail: protetti@smail.com 
